\title{
Transcriptomic and Functional Studies of the RGS Protein Rax1 in Aspergillus fumigatus
}

\author{
Yong-Ho Choi ${ }^{1, \dagger}{ }^{\text {, Min-Woo Lee }}{ }^{2, \dagger}$, Olumuyiwa Ayokunle Igbalajobi ${ }^{3}$, Jae-Hyuk Yu ${ }^{4,5, * \mathbb{C} \text { and }}$ \\ Kwang-Soo Shin $1, *$ (D) \\ 1 Department of Microbiology, Graduate School, Daejeon University, Daejeon 34520, Korea; \\ youngho1107@gmail.com \\ 2 Soonchunhyang Institute of Medi-bio Science, Soonchunhyang University, \\ Chungcheongnam-do 31151, Korea; mwlee12@sch.ac.kr \\ 3 Department of Microbiology, Institute for Applied Biosciences, Karlsruhe Institute of Technology, \\ Fritz-Haber Weg 4, D-76131 Karlsruhe, Germany; olumuyiwa.igbalajobi@kit.edu \\ 4 Departments of Bacteriology and Genetics, University of Wisconsin-Madison, Madison, WI 53706, USA \\ 5 Department of Systems Biotechnology, Konkuk University, Seoul 05029, Korea \\ * Correspondence: jyu1@wisc.edu (J.-H.Y.); shinks@dju.kr (K.-S.S.) \\ + Contributed equally to this work.
}

Received: 6 December 2019; Accepted: 30 December 2019; Published: 31 December 2019

\begin{abstract}
In the comparative transcriptomic studies of wild type (WT) and rax1 null mutant strains, we obtained an average of 22,222,727 reads of $101 \mathrm{bp}$ per sample and found that 183 genes showed greater than 2.0-fold differential expression, where 92 and 91 genes were up-and down-regulated in $\Delta \operatorname{rax} 1$ compared to $\mathrm{WT}$, respectively. In accordance with the significantly reduced levels of gliM and cas $B$ transcripts in the absence of $\operatorname{rax} 1$, the $\triangle \operatorname{rax} 1$ mutant exhibited increased sensitivity to exogenous gliotoxin (GT) without affecting levels of GT production. Moreover, $\Delta$ rax1 resulted in significantly restricted colony growth and reduced viability under endoplasmic reticulum stress condition. In summary, Rax1 positively affects expression of gliM and metacaspase genes.
\end{abstract}

Keywords: Aspergillus fumigatus; GliM; metacaspase; Rax1; RNA-seq

\section{Introduction}

The $G$ protein signaling pathway plays central roles in transmitting environmental stimuli into intrinsic signals leading to appropriate gene expression changes. Binding of an external ligand to an associated $\mathrm{G}$ protein coupled receptor (GPCR) causes GDP-to-GTP exchange of a $\mathrm{G} \alpha$, which then results in dissociation of $G \alpha$-GTP and $G \beta \gamma$ subunits. Dissociated (activated) $G$ protein subunits interact with downstream effectors leading to activation of various signaling pathways involving cAMP-dependent protein kinase A (PKA), mitogen activated protein kinases (MAPKs), or protein kinase C (PKC) [1-3]. One of the key control points of these signaling pathways is at the $G$ protein level exerted by regulators of $G$ protein signaling (RGSs). Normally, an RGS protein interacts with its target $G \alpha$-GTP subunit and activates intrinsic GTPase activity of the G $\alpha$-GTP, leading to accelerated GTP to GDP hydrolysis. $\mathrm{G} \alpha$-GDP then associates with its G $\beta \gamma$ subunit, leading to turn-off of the $G$ protein-mediated signaling pathway [2,4].

In the genome of the opportunistic human pathogenic fungus Aspergillus fumigatus, six RGS proteins that contain the conserved RGS domain have been identified based on homology searches, and the roles of them have been characterized [5-10]. Previously, we reported that Rax1 of A. fumigatus positively controls vegetative growth and asexual development. In addition, the rax 1 null mutant conidia were more resistant against exogenous $\mathrm{H}_{2} \mathrm{O}_{2}$ via elevated accumulation of intracellular 
trehalose and cell wall melanin [7]. In the present study, to further understand the functions of Rax1, we carried out RNA-Seq-based transcriptome analyses of wild types (WT) and rax1 null mutants. In addition, follow-up functional studies corroborating the findings of genome-wide expression analyses are reported.

\section{Results}

\subsection{Summary of the RNA-Seq Data}

For the comparative RNA-seq analysis between WT and $\Delta$ rax 1 strain, cells were collected at $12 \mathrm{~h}$ cultures as described in Materials and Methods. Correlation of overall gene expression between WT and $\Delta$ rax 1 strain was highly correlated $(\mathrm{R}=0.95$, Figure $1 \mathrm{~A})$. The A. fumigatus genome contains 9840 protein, 205 tRNA, 34 rRNA, 29 snoRNA, 12 ncRNA, and 9 snRNA coding genes with 1 pseudogene (AspGD: http://www.aspergillusgenome.org). We obtained an average of 22,222,727 reads and 9,836 different transcripts for $\Delta$ rax 1 strain. Of the 9,836 genes, 1,300 genes (13.2\%) displayed more than 2.0-fold $\left(\log _{2} \mathrm{FC}=1.0\right)$ changes in mRNA levels (Figure 1B), of which $957(9.7 \%)$ exhibited higher transcript levels in the $\Delta \operatorname{rax} 1$ strain than in the WT strain whereas $343(3.5 \%)$ were down-regulated in the $\Delta$ rax 1 strain. Among them, statistically significant $(p<0.05)$ genes were 92 and 91 , respectively (Tables S1 and S2).

\subsection{Functional Category Analysis}

Functional category analysis was performed by determining gene ontology (GO) terms that were enriched in differentially expressed genes (DEGs). The most represented molecular function GO categories are "Catalytic activity", with 31 down- and 18 up-regulated, and "Oxidoreductase activity" with 13 up- and 7 down-regulated. The top significant cellular component GO categories are "Intrinsic and integral component of membrane" (19 up, 8 down). The most significant biological process GO categories are "Metabolic process" (26 up, 15 down), "Oxidation-reduction process" (13 up, 7 down), "Localization" (9 up, 3 down), and "Response to stimulus" ( 2 up, 3 down) (Figure 1C). Table S1 lists the at least 2.0-fold $\left(\log _{2} \mathrm{FC}=1.0\right)$ up-regulated genes with $(p<0.05)$ following the deletion of rax1. The highest up-regulated gene was an emopamil binding protein (EBP) domain protein encoding gene (AFUA 1G15100), which is involved in sterol metabolic process and a majority of up-regulated genes encodes hypothetical proteins. Most of the down-regulated genes were transcription factors and transporters (Table S2), including Zn(II)2Cys6 transcription factors (AFUA 7G05080, 8G02280, 4G01322, and 2G04860) and major facilitator superfamily (MFS) transporters (AFUA 7G05190, 3G00540, 6G02400, 3G02060, 2G12500, 2G17360, 3G01670, and 3G03190). 
A

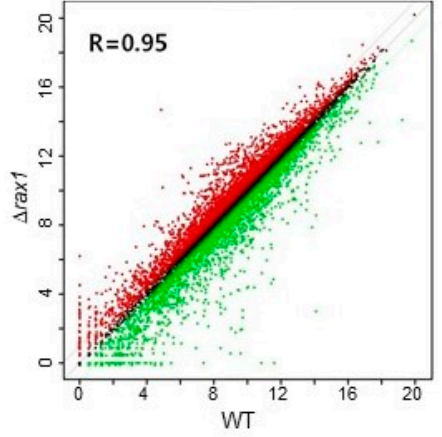

B

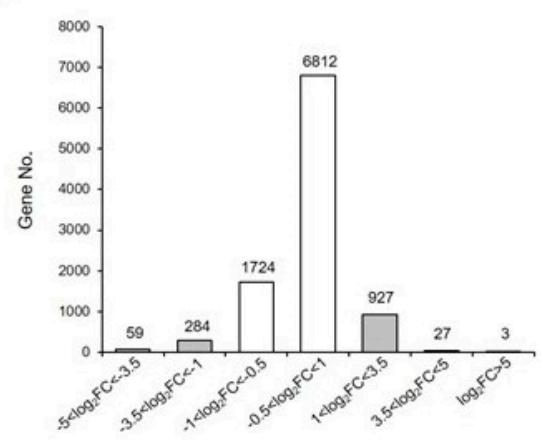

C

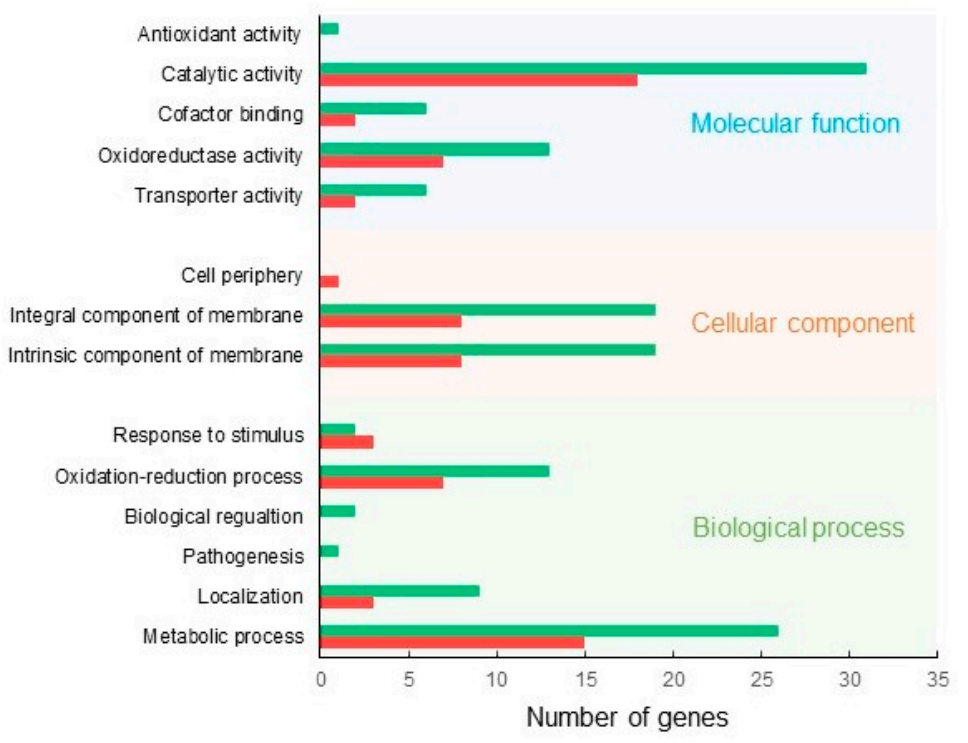

Figure 1. Summary of the transcriptomic analyses of wild type (WT) and $\Delta$ rax 1 strains. (A) Linear fitted model showing the correlation of overall gene expression between WT and $\Delta \operatorname{rax} 1$ strains. The correlation coefficient $(\mathrm{R}=0.95)$ is indicated. (B) Histograms showing general transcriptomic results where the white bars fall in the $-1<\log _{2} \mathrm{FC}<1$ fragment count range with low differential expression values. (C) Functional categories of DEGs. Genes associated with increased mRNA levels in the $\Delta \operatorname{rax} 1$ strain are represented with red bars and genes associated with decreased mRNA levels in the mutant strain are represented with green bars.

\subsection{Rax1 Functions in the Resistance against Exogenous Gliotoxin}

The most down-regulated gene by $\Delta \operatorname{rax} 1$ was the one encoding the O-methyltransferase GliM ( $\log _{2} \mathrm{FC}=-10.83$ ). To assess RNA-seq result, we estimated the mRNA levels of gliM by qRT-PCR. As shown in Figure 2A, level of gliM transcript in mutant strain was significantly lower (about 0.025-fold) than that of WT. GliM catalyzes the conversion of reduced dithiol gliotoxin (GT) to bisthiomethyl gliotoxin and plays a role in protecting fungi against dithiol containing toxins [11]. The production of GT analyzed by TLC and the relative intensity of GT of WT, $\Delta$ rax 1 , and complemented ( $\left.\mathrm{C}^{\prime}\right)$ strains was 16.2,16.1, and 17.2, respectively, implying that GT production was not affected by the absence of rax1 (Figure 2B). We also checked the effect of Rax1 on the virulence in the CD1 (ICR) female mice. Conidia of three strains were inoculated in mice, and monitored every $12 \mathrm{~h}$ for survival for 4 days after challenge. The virulence of $\Delta \operatorname{rax} 1$ strains was avirulent compared to WT and $\mathrm{C}^{\prime}$ strains (Figure 2C). Comparison of survival curves analyzed by a log rank test revealed that there was no meaningful difference between the three strains $(p=0.7919)$. To test the effect of reduced expression of gliM in the $\Delta$ rax1 strain, we checked the tolerance of the mutant to exogenous GT in comparison to WT. When conidia of three strains were inoculated in the presence of GT, the radial growth of all strains was decreased compared to untreated controls. While the growth of WT and $\mathrm{C}^{\prime}$ strains were decreased about $30 \%$, which of $\Delta \operatorname{rax} 1$ strain was decreased about $40 \%$ (Figure 2D), indicating that the $\Delta \operatorname{rax} 1$ mutant was more sensitive than WT and $C^{\prime}$ strains against exogenous GT. These results suggest that Rax1 is required for proper expression of gliM leading to the self-protection against exogenous GT, but not de novo biosynthesis of GT. 
A

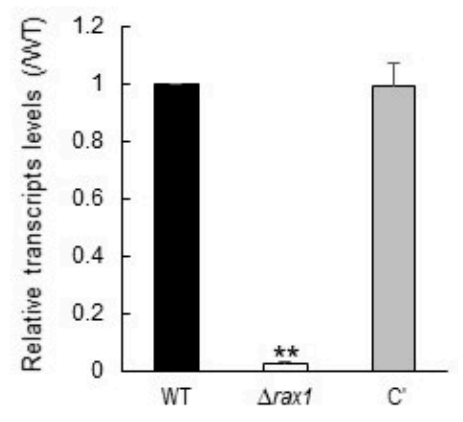

C

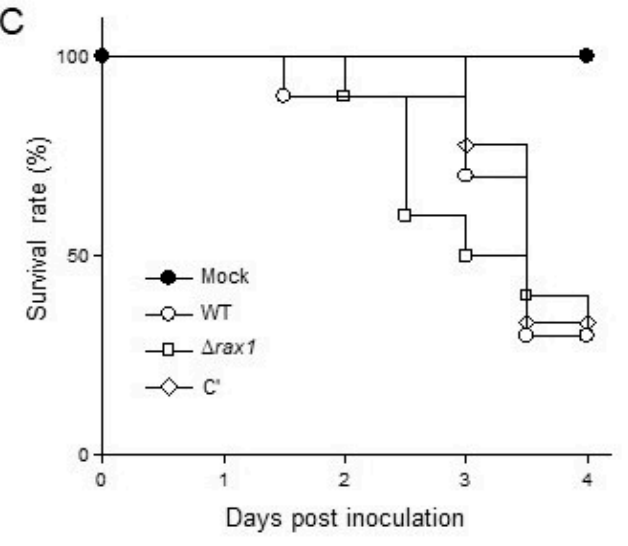

B

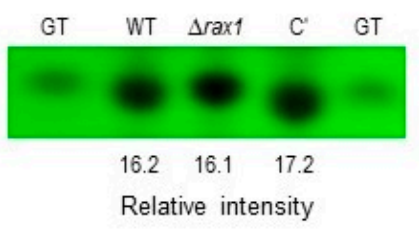

D
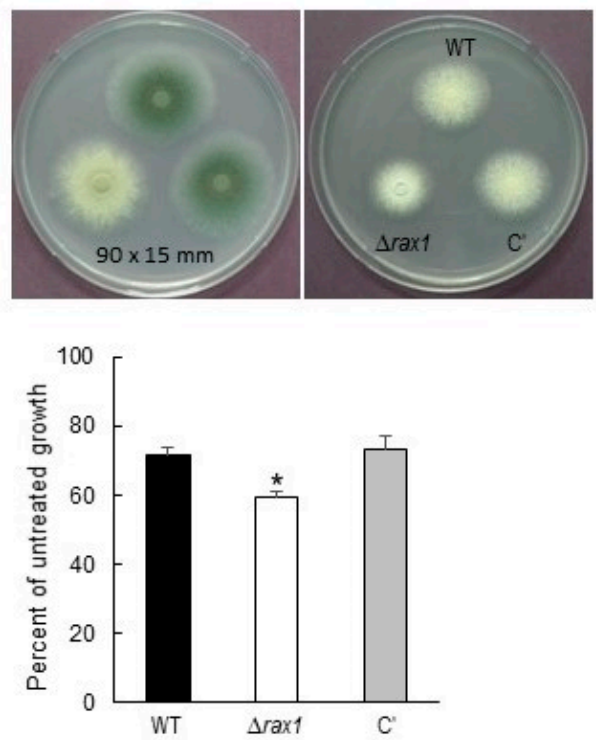

Figure 2. Roles of Rax1 in gliotoxin (GT) production, virulence, and tolerance to exogenous GT. (A) Levels of gliM transcript analyzed by qRT-PCR. (B) GT production in WT, $\Delta$ raxi, and $\mathrm{C}^{\prime}$ strains. The culture supernatant of each strain was extracted with chloroform and subjected to TLC. (C) Kaplan-Meier plots of the survival of ICR mice after infection with three strains of conidia. (D) Effect of exogenous GT on the growth of three strains of conidia. Conidia $\left(1 \times 10^{5}\right)$ of each strain was inoculated in glucose minimal medium (MMG) containing GT (10 $\mu \mathrm{g} / \mathrm{mL})$ and incubated at $37^{\circ} \mathrm{C}$ for $48 \mathrm{~h}$. Statistical differences were evaluated with an ANOVA test. ${ }^{*} p<0.05$.

\subsection{Rax1 Positively Regulates Metacaspase Activity}

In RNA-seq analysis, we found that the transcript encoding the metacaspase CasB was significantly down-regulated $\left(\log _{2} \mathrm{FC}=-2.90\right)$ in the $\Delta \operatorname{rax} 1$ mutant compared to WT (Table S3). To test whether Rax1 affects metacaspases expression, qRT-PCR analysis for the cas $A$ and cas $B$ transcript was carried out. The deletion of rax 1 led to reduced mRNA levels of metacaspase encoding genes (Figure 3A). To test sensitivity against endoplasmic reticulum (ER) homeostasis disrupting agents, radial growth and survival rates of three strains were determined in the presence of dithiothreitol (DTT), 2-deoxy-D-glucose (2-DG), and brefeldin A (BFA). The radial growth of the mutant was reduced by the treatment of DTT and 2-DG (Figure 3B). Markedly, the $\Delta \operatorname{rax} 1$ mutant exhibited significantly restricted vegetative growth on the medium containing $0.1 \%$ 2-DG as the sole carbon source (about $50 \%$ of WT and $\mathrm{C}^{\prime}$ strains) (Figure 3B). Against another ER stressor BFA, as shown in Figure 3C, while viability of WT and $\mathrm{C}^{\prime}$ strains was about $47 \%$, but that of $\triangle \operatorname{rax} 1$ strain was $35 \%$ indicating that it is likely that $\triangle \operatorname{rax} 1 \mathrm{might}$ lead to reduced tolerance to BFA (Figure 3C). 
A

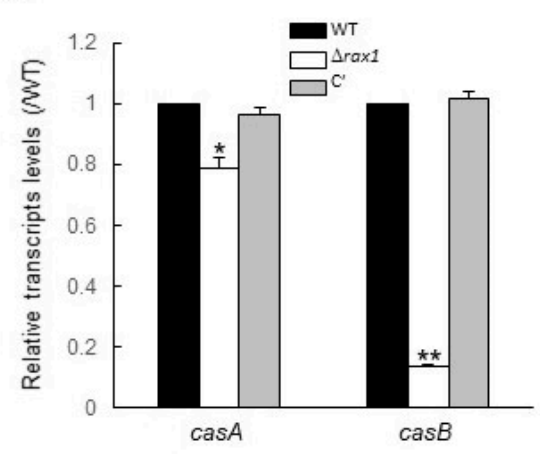

C

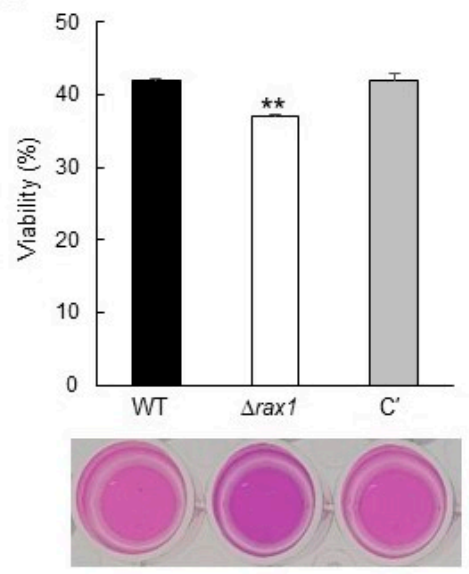

B
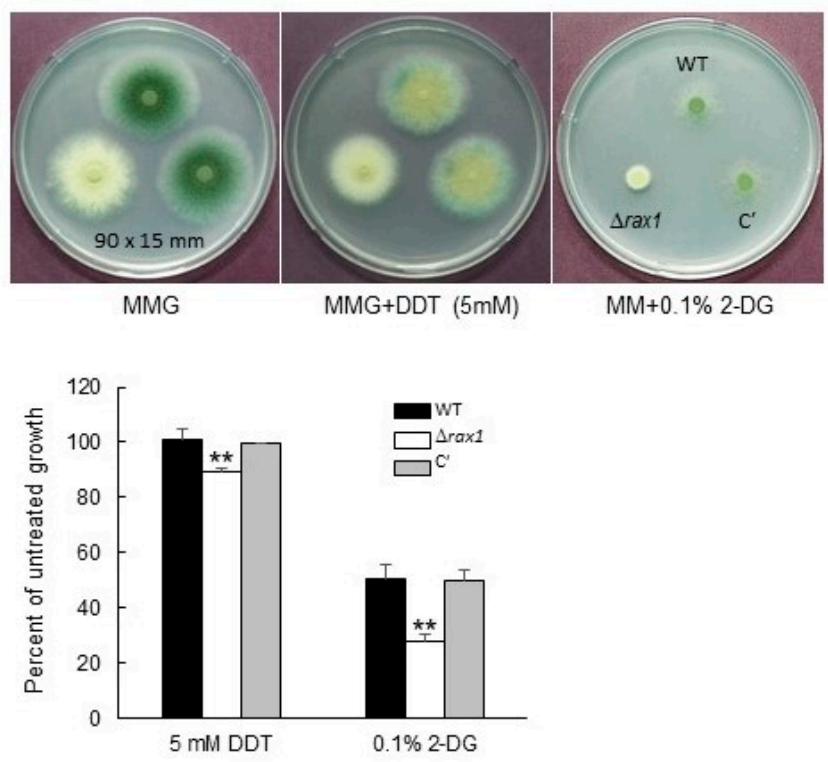

Figure 3. The $\Delta \operatorname{rax} 1$ mutant shows enhanced sensitivity to ER stressors. (A) qRT-PCR analysis of the metacaspase genes in WT, $\Delta r a x 1$, and $C^{\prime}$ strains. (B) Same numbers of conidia $\left(5 \times 10^{5}\right)$ from the three strains were spotted into $5 \mathrm{mM}$ dithiothreitol (DTT) and 0.1\% 2-deoxy-D-glucose (2-DG) containing media and determined radial growth rate. (C) Approximate $10^{4}$ conidia were inoculated into $2 \mathrm{~mL}$ of glucose minimal medium (MMG) containing brefeldin A (BFA), incubated at $37^{\circ} \mathrm{C}$ for $48 \mathrm{~h}$, and detected cell viability with alamarBlue $(\mathrm{AB})$. Statistical differences were evaluated with an ANOVA test. ** $p<0.01$.

\section{Discussion}

RGSs are a group of proteins including conserved RGS box that interacts with a GTP-G $\alpha$ subunit and turn-off the G protein signaling pathways [4]. One of the A. fumigatus RGS, Rax1 (RgsB) protein, is similar to ScRax1P of the yeast Saccharomyces cerevisiae, where ScRax1P is required for the establishment of the bipolar budding [12]. However, the function of its homologous proteins is poorly understood in filamentous fungi. Previously, we reported that Rax1 of A. fumigatus positively controls growth, development, and oxidative stress response [7]. To further understand the functions of Rax1, we carried out RNA-Seq-based genome-wide expression studies and additional functional investigation.

Based on the transcriptome analysis, we found that a large number of genes are down-regulated in the $\Delta \operatorname{rax} 1$ strain compared to the WT strain. At first, we focused on the most down-regulated gene, gliM. The gliM gene is located in the GT biosynthetic gene cluster that comprises 13 genes $[13,14]$ and encodes an O-methyltransferase. Disruption of gliM completely abrogated bis-methyl gliotoxin biosynthetic ability, while GT production and secretion was unaffected [11]. By modification of the active dithiol form of GT to an inactive bis-thiomethylated form, the GT producing fungi are protected from dithiol end products and/or toxic biosynthetic intermediates. In accordance with these, while there were no significant differences in the production of GT between strains, growth of the $\Delta \operatorname{rax} 1$ strain was more inhibited by exogenous GT compared to WT and $\mathrm{C}^{\prime}$ strains (Figure 2). 
The caspase plays a central role in apoptosis and can be classified into the metazoan caspase family, paracaspase family, and metacaspase family [15]. The metacaspase family is specific to plant, fungi, and protozoa. A. fumigatus has two metacaspases, CasA and CasB, which function in both apoptotic morphology and resistance to ER stress [16]. The metacaspase deletion mutants showed a growth detriment in ER stress conditions [16]. In RNA-seq and qRT-PCR analyses, the expression of both metacaspases was significantly decreased by loss of $\operatorname{rax} 1$ (Figure 3A, Table S2). Moreover, growth of the $\Delta \operatorname{rax} 1$ strain was impaired on medium containing DTT and 2-DG, which induces ER stress $[17,18]$. The sensitivity to ER stressor was confirmed using BFA, which generates ER stress by blocking the transport of proteins to the Golgi apparatus [19]. Viability of the $\Delta \operatorname{rax} 1$ strain was significantly reduced compared to WT and $C^{\prime}$ strains in the presence of BFA (Figure 3C). Metacaspase-deficient mutants showed similar results. Loss of either cas $A$ or $\operatorname{cas} B$ resulted in impaired radial growth on medium containing 2-DG and tunicamycin that induces ER stress in fungi $[18,20,21]$, and loss of both genes had an additive effect. From these results, it can be concluded that Rax1 is required for normal growth of $A$. fumigatus in the ER homeostasis perturbation conditions by positively regulating CasA and CasB.

\section{Materials and Methods}

\subsection{Strains and Culture Conditions}

Glucose minimal medium (MMG) and MMG with 0.1\% yeast extract (MMY) with appropriate supplements were used for culture of wild type (AF293) and the rax1 null mutant strains [7]. Conidia were propagated MMY for 5 days at $37^{\circ} \mathrm{C}$ and were collected with $0.02 \%$ Tween 80 . The suspension was passed through a Miracloth (Millipore, Burlington, MA, USA) to remove hyphae and counted using a hemocytometer. To examine production of secondary metabolites, spores of relevant strains were inoculated at a final concentration of $5 \times 10^{5}$ conidia/mL to $50 \mathrm{~mL}$ of liquid MMY with appropriate supplements and incubated at $250 \mathrm{rpm}$ at $37^{\circ} \mathrm{C}$ for 4 days.

\subsection{Nucleic Acid Manipulation}

Total RNA isolation and quantitative RT-PCR (qRT-PCR) assays were was carried out as previously described [5,22]. Briefly, conidia $\left(5 \times 10^{5}\right.$ conidia/mL) of WT, $\Delta$ rax 1 , and C strains were inoculated into MMY liquid media with appropriate supplements and incubated at $37^{\circ} \mathrm{C}, 250 \mathrm{rpm}$. Mycelial samples were collected and squeeze-dried at indicated time points. The sample was homogenized using a Mini Bead beater in the presence of silica/zirconium beads $(0.3 \mathrm{~mL}$, BioSpec Products, Bartlesville, OK, USA) and TRIzol ${ }^{\circledR}$ reagent $(1.0 \mathrm{~mL}$, Invitrogen, Carlsbad, CA, USA). Quantitative RT-PCR (qRT-PCR) assays were carried out according to the manufacturer's instruction using a Rotor-Gene Q (Qiagen, Hilden, Germany). Each run was assayed in triplicate with the RNA template, One Step RT-PCR SYBR Mix (MGmed, Seoul, Korea), reverse transcriptase (MGmed, Korea), and 10 pmole of each primer (Table S3). The data were normalized to ef1 $\alpha$ expression [10] and calculated according to the $\Delta \Delta C \mathrm{t}$ method [22].

\subsection{RNA-Seq Experiment}

For RNA-seq analyses, cellophane sheet was spread out on the agar medium and $50 \mu \mathrm{L}$ of a conidial suspension $\left(10^{7} / \mathrm{mL}\right)$ was inoculated onto the cellophane. The plates were incubated in the dark at $37^{\circ} \mathrm{C}$ for $12 \mathrm{~h}$. We collected fungal colonies in triplicate and they were immediately frozen in liquid nitrogen and ground into a fine powder with a mortar and pestle. Total RNA was extracted as in the above described method. After analysis of RNA quality, three RNA samples from the same strain were combined and analyzed. This was done in duplicate. Total RNA was submitted to eBiogen Inc. (Seoul, Korea) for further analyses. RNA-Seq reads were mapped using TopHat software v2.1.0 tool in order to obtain the alignment file and Aspergillus fumigatus Database (NCBI) was used as the template for mapping. The alignment file was used to assemble transcripts, estimate their abundances, and detect differential expression of genes or isoforms using Cufflink v2.2.1. Gene classification was done based 
on searches done by BioCarta (http://www.biocarta.com/), GenMAPP (http://www.genmapp.org/), DAVID (http://david.abcc.ncifcrf.gov/), and Medline databases (http://www.ncbi.nlm.nih.gov/).

\subsection{Phenotype Analyses}

The tolerance to gliotoxin (GT, Sigma-Aldrich, Saint Louis, MO, USA) was tested with conidia of WT and mutant strains. Each conidia was inoculated onto MMG plates with the presence or absence of GT $(10 \mu \mathrm{g} / \mathrm{mL})$ and incubated at $37^{\circ} \mathrm{C}$ for $48 \mathrm{~h}$ [14]. GT was extracted with chloroform as described previously [23] and analyzed by a thin-layer chromatography (TLC) silica plate (Kiesel gel 60, E. Merck). The TLC plate was developed with chloroform:methanol $(9: 1, v / v)$. For test of ER stress responses, DTT $(5 \mathrm{mM})$ was added into MMG and 2-DG was used in place of glucose at $0.1 \%(w / v)$ in MMG solid medium. To assess sensitivity to BFA, conidia $\left(1 \times 10^{4}\right)$ were inoculated into $2 \mathrm{~mL}$ of MMG containing BFA (1 $\times)$ and incubated at $37^{\circ} \mathrm{C}$ for $48 \mathrm{~h}$. Cell viability was determine using alamarBlue (AB) assay based on the percent reduction of $\mathrm{AB}$ as described previously [24].

\subsection{Murine Virulence Assay}

For the persistently neutropenic mouse model, we used outbred ICR (Orient Bio Inc., Seongnam-si, Korea) female mice ( $30 \mathrm{~g}$ in body weight, 6 to 8 weeks old), which were housed five per cage and had access to food and water ad libitum. Mice were immunosuppressed with intraperitoneal injections (i.p.) of cyclophosphamide (Sigma-Aldrich, USA) at $250 \mathrm{mg} / \mathrm{kg}$ for 4 days prior to infection and with cyclophosphamide at $250 \mathrm{mg} / \mathrm{kg}$ and cortisone acetate (Sigma-Aldrich, USA) injected subcutaneously at $250 \mathrm{mg} / \mathrm{kg} 1$ day prior to infection. At day 1 and 3 day post-infection, administrations were repeated with cyclophosphamide ( $125 \mathrm{mg} / \mathrm{kg}$ i.p.). Mice were anesthetized with isoflurane and then intranasally infected with $1 \times 10^{7}$ conidia of $A$. fumigatus strains (10 mice per each strain) in $30 \mu \mathrm{L}$ of $0.01 \%$ Tween 80 in PBS. Mice were observed every $12 \mathrm{~h}$ for survival for 4 days after challenge. Mock mice were inoculated with sterile $0.01 \%$ Tween 80 in PBS.

\subsection{Statistical Analyses}

Comparison of mRNA expressions, radial growth, and viability within the different strains were performed by one-way ANOVA tests. All results were expressed as means \pm standard deviation (SD) and a $p$ value less than 0.05 was considered statistically significant. Analyses of survival rates were performed by creating Kaplan-Meier plots and then performing log rank tests (GraphPad Prism 7.0). And comparisons for survival studies were considered significant if the $p$ value was $<0.05$.

\subsection{Ethics Statement}

All of the animal procedures in this study were reviewed and approved by the Institutional Animal Care and Use Committee of Daejeon University (DJUARB2019-024).

\subsection{Data Availability}

The RNA-seq data are available from NCBI Gene Expression Omnibus (GEO) database under the accession number GSE100101.

Supplementary Materials: The following are available online at http://www.mdpi.com/2076-0817/9/1/36/s1. Table S1: Up-regulated genes in $\Delta$ rax 1 relative to WT $(p<0.05)$, Table S2: Down-regulated genes in $\Delta$ rax 1 relative to WT $(p<0.05)$, Table S3: Oligonucleotides used in this study.

Author Contributions: K.-S.S. and J.-H.Y. conceived and supervised the study; K.-S.S., J.-H.Y., and M.-W.L. designed experiments; Y.-H.C., M.-W.L., O.A.I., and K.-S.S. performed experiments; K.-S.S. and J.-H.Y. analyzed data; Y.-H.C., M.-W.L., J.-H.Y., and K.-S.S. wrote the manuscript. All authors have read and agreed to the published version of the manuscript.

Funding: This work was supported by the National Research Foundation of Korea (NRF) grant funded by the Korea government (MSIP) (No. 2017R1A2B4001806) to K.S. Shin. The work at UW was supported by Food 
Research Institute and the University of Wisconsin-Madison Office of the Vice Chancellor for Research and Graduate Education (OVCRGE) with funding from the Wisconsin Alumni Research Foundation to J.H. Yu.

Acknowledgments: We thank all our lab members for helpful discussions.

Conflicts of Interest: The authors declare that they have no conflict of interest.

\section{References}

1. Morris, A.J.; Malbon, C.C. Physiological regulation of G protein-linked signaling. Physiol. Rev. 1999, 79, 1373-1430. [CrossRef] [PubMed]

2. McCudden, C.R.; Hains, M.D.; Kimple, R.J.; Siderovski, D.P.; Willard, F.S. G-protein signaling: Back to the future. Cell. Mol. Life Sci. 2005, 62, 551-577. [CrossRef] [PubMed]

3. Feldbrugge, M.; Kamper, J.; Steinberg, G.; Kahmann, R. Regulation of mating and pathogenic development in Ustilago maydis. Curr. Opin. Microbiol. 2004, 7, 666-672. [CrossRef] [PubMed]

4. Yu, J.H. Heterotrimeric G protein signaling and RGSs in Aspergillus nidulans. J. Microbiol. 2006, 44, $145-154$. [PubMed]

5. Mah, J.H.; Yu, J.H. Upstream and downstream regulation of asexual development in Aspergillus fumigatus. Eukaryot. Cell. 2006, 5, 1585-1595. [CrossRef] [PubMed]

6. Jung, M.G.; Kim, S.S.; Yu, J.H.; Shin, K.S. Characterization of gprK encoding a putative hybrid G-protein-coupled receptor in Aspergillus fumigatus. PLoS ONE 2016, 11, e0161312. [CrossRef] [PubMed]

7. Igbalajobi, O.A.; Yu, J.H.; Shin, K.S. Characterization of the $\operatorname{rax} 1$ gene encoding a putative regulator of G protein signaling in Aspergillus fumigatus. Biochem. Biophys. Res. Commun. 2017, 487, 426-432. [CrossRef]

8. Kim, Y.; Heo, I.B.; Yu, J.H.; Shin, K.S. Characteristics of a regulator of G-protein signaling (RGS) $r g s C$ in Aspergillus fumigatus. Front. Microbiol. 2017, 8, 2058. [CrossRef]

9. Kim, Y.; Lee, M.W.; Jun, S.C.; Choi, Y.H.; Yu, J.H.; Shin, K.S. RgsD negatively controls development, toxigenesis, stress response, and virulence in Aspergillus fumigatus. Sci. Rep. 2019, 9, 811. [CrossRef]

10. Lwin, H.P.; Choi, Y.H.; Lee, M.W.; Yu, J.H.; Shin, K.S. RgsA attenuates the PKA signaling, stress response, and virulence in the human opportunistic pathogen Aspergillus fumigatus. Int. J. Mol. Sci. 2019, 20, 5628. [CrossRef]

11. Dolan, S.K.; Bock, T.; Hering, V.; Owens, R.A.; Jones, G.W.; Blankenfeldt, W.; Doyle, S. Structural, mechanistic and functional insight into gliotoxin bis-thiomethylation in Aspergillus fumigatus. Open Biol. 2017, 7, 160292. [CrossRef] [PubMed]

12. Fujita, A.; Lord, M.; Hiroko, T.; Hiroko, F.; Chen, T.; Oka, C.; Misumi, Y.; Chant, J. Rax1, A protein required for the establishment of the bipolar budding pattern in yeast. Gene 2004, 327, 161-169. [CrossRef] [PubMed]

13. Gardiner, D.M.; Waring, P.; Howlett, B.J. The epipolythiodioxopiperazine (ETP) class of fungal toxins: Distribution, mode of action, functions and biosynthesis. Microbiology 2005, 151, 1021-1032. [CrossRef] [PubMed]

14. Schrettl, M.; Carberry, S.; Kavanagh, K.; Haas, H.; Jones, G.W.; O’Brien, J.; Nolan, A.; Stephens, J.; Fenelon, O.; Doyle, S. Self-protection against gliotoxin-A component of the gliotoxin biosynthetic cluster, GliT, completely protects Aspergillus fumigatus against exogenous gliotoxin. PLoS Pathog. 2010, 6, e1000952. [CrossRef]

15. Uren, A.G.; O’Rourke, K.; Aravind, L.A.; Pisabarro, M.T.; Seshagiri, S.; Koonin, E.V.; Dixit, V.M. Identification of paracaspases and metacaspases: Two ancient families of caspase-like proteins, one of which plays a key role in MALT lymphoma. Mol. Cell. 2000, 6, 961-967. [CrossRef]

16. Richie, D.L.; Miley, M.D.; Bhabhra, R.; Robson, G.D.; Rhodes, J.C.; Askew, D.S. The Aspergillus fumigatus metacaspases CasA and CasB facilitate growth under conditions of endoplasmic reticulum stress. Mol. Microbiol. 2007, 63, 591-604. [CrossRef]

17. Helenius, A.; Aebi, M. Roles of N-linked glycans in the endoplasmic reticulum. Annu. Rev. Biochem. 2004, 73, 1019-1049. [CrossRef]

18. Back, S.H.; Schroder, M.; Lee, K.; Zhang, K.; Kaufman, R.J. ER stress signaling by regulated splicing: IRE1/HAC1/XBP1. Methods 2005, 35, 395-416. [CrossRef]

19. Citterio, C.; Vichi, A.; Pacheco-Rodriguez, G.; Aponte, A.M.; Moss, J.; Vaughan, M. Unfolded protein response and cell death after depletion of brefeldin A-inhibited guanine nucleotide-exchange protein GBF1. Proc. Natl. Acad. Sci. USA 2008, 105, 2877-2882. [CrossRef] 
20. Al-Sheikh, H.; Watson, A.J.; Lacey, G.A.; Punt, P.J.; MacKenzie, D.A.; Jeenes, D.J.; Pakula, T.; Penttila, M.; Alcocer, M.J.; Archer, D.B. Endoplasmic reticulum stress leads to the selective transcriptional downregulation of the glucoamylase gene in Aspergillus niger. Mol. Microbiol. 2004, 53, 1731-1742. [CrossRef]

21. Arvas, M.; Pakula, T.; Lanthaler, K.; Saloheimo, M.; Valkonen, M.; Suortti, T.; Robson, G.; Penttila, M. Common features and interesting differences in transcriptional responses to secretion stress in the fungi Trichoderma reesei and Saccharomyces cerevisiae. BMC Genom. 2006, 7, 32. [CrossRef] [PubMed]

22. Livak, K.J.; Schmittgen, T.D. Analysis of relative gene expression data using real-time quantitative PCR and the $2^{-\Delta \Delta C T}$ Method. Methods 2001, 25, 402-408. [CrossRef] [PubMed]

23. Bok, J.W.; Keller, N.P. LaeA, A regulator of secondary metabolism in Aspergillus spp. Eukaryot. Cell 2004, 3, 527-535. [CrossRef] [PubMed]

24. Shin, K.S.; Kwon, N.J.; Kim, Y.H.; Park, H.S.; Kwon, G.S.; Yu, J.H. Differential roles of the ChiB chitinase in autolysis and cell death of Aspergillus nidulans. Eukaryot. Cell 2009, 8, 738-746. [CrossRef] [PubMed]

(C) 2019 by the authors. Licensee MDPI, Basel, Switzerland. This article is an open access article distributed under the terms and conditions of the Creative Commons Attribution (CC BY) license (http://creativecommons.org/licenses/by/4.0/). 